OPEN ACCESS

Edited by:

Marina Rufino Salinas Fortes,

The University of Queensland,

Australia

Reviewed by: Kasey Lane DeAtley,

California State University,

Chico, United States

Milt Thomas,

Colorado State University,

United States

*Correspondence:

Rodrigo Ramos Catharino

rrc@g.unicamp.br

Specialty section:

This article was submitted to Animal Reproduction - Theriogenology, a section of the journal Frontiers in Veterinary Science

Received: 31 October 2017 Accepted: 18 January 2018 Published: 08 February 2018

Citation:

Guerreiro TM, Gonçalves RF,

Melo CFOR, de Oliveira DN, Lima EdO, Visintin JA,

de Achilles MA and Catharino RR (2018) A Metabolomic Overview

of Follicular Fluid in Cows.

Front. Vet. Sci. 5:10.

doi: 10.3389/fvets.2018.00010

\section{A Metabolomic Overview of Follicular Fluid in Cows}

\author{
Tatiane Melina Guerreiro', Roseli Fernandes Gonçalves², Carlos Fernando O. Rodrigues \\ Melo', Diogo Noin de Oliveira ${ }^{1}$, Estela de Oliveira Lima ${ }^{1}$, Jose Antônio Visintin ${ }^{2}$, \\ Marcos Antônio de Achilles ${ }^{3}$ and Rodrigo Ramos Catharino ${ }^{1 *}$

\begin{abstract}
${ }^{1}$ Innovare Biomarkers Laboratory, School of Pharmaceutical Sciences, University of Campinas - UNICAMP, Campinas, São Paulo, Brazil, ' ${ }^{2}$ Department of Animal Reproduction, College of Veterinary Medicine and Animal Science, São Paulo University - USP, São Paulo, Brazil, ${ }^{3}$ Achilles Genetics, Garça, Brazil
\end{abstract}

Follicular fluid (FF) protects the oocyte against proteolysis and extrusion during ovulation, providing an appropriate microenvironment that favors proper embryonic development; thereby, FF plays a key role in embryo quality. Being directly related to cattle breeding, studying FF is extremely important in livestock science to measure cattle fertility. This may eventually help to assess the quality of both meat and milk, products widely consumed worldwide. There is an important commercial interest in the evaluation and characterization of compounds present in the FF of livestock that present greater likelihood of pregnancy. Mass spectrometry is a great ally for this type of analysis and can provide quick and efficient screening for molecular markers in biological samples. The present study demonstrated the potential of high-resolution mass spectrometry in analyzing FF samples from two distinct groups of Nellore cows (Bos indicus): high and low fertility, as determined by the number of oocytes produced. We were able to delineate markers of interest for each group, which may ultimately be related to biochemical pathways that lead to higher or lower reproductive performance.

Keywords: follicular fluid, fertility, molecular markers, cows, oocyte quality

\section{INTRODUCTION}

In the past 40 years, beef and dairy cattle were subject to intense selection, especially in terms of genetic engineering, primarily focusing on the improvement of milk and meat production (1). More recently, due to technological advances, it was observed that the infertility in dairy cows has decreased in the last few years $(2,3)$; nonetheless, despite optimistic numbers, infertility in cows is still a subject of great economic interest $(4,5)$. Hence, there is great demand to investigate the physiology and pathogenesis that are the triggering factors for infertility. It is currently known that this is a condition associated with both genetic and environmental elements, and the role of oocyte and embryo quality in the final fertility is the most noteworthy feature discussed in recent literature $(6,7)$. Newer platforms, such as transcriptomics, proteomics, and metabolomics, have been increasingly assisting researchers and clinicians in investigating and selecting oocytes and embryos using sophisticated methods. Follicular fluid (FF), follicular cells, and cumulus cells are fluids and tissues previously considered superfluous for analyses associated with oocyte quality. However, the trend of performing noninvasive sampling and evaluations has been increasing recently, giving a whole new relevance for the use of these samples (8). 
Follicular fluid is responsible for providing oocyte protection against proteolysis, as well as aiding in the extrusion process during ovulation (9), acting as a buffer against adverse blood influences (10). Researchers have proposed and demonstrated in postpartum cows that there is a close correlation between the levels of certain metabolites in both: FF and blood serum. Thus, potential variations in serum concentrations of metabolites may affect FF, which may lead to changes in the quality of granulosa and oocyte cells (11). Therefore, since FF provides an appropriate microenvironment for the oocyte that leads to proper embryonic development, it is partly responsible for embryo quality $(12,13)$.

Currently, FF has been used for conservation and maturation of oocytes, with the purpose of performing in vitro fertilization in cattle (14). This use is justified due to the high protein content found in its constitution, even greater than that presented by fetal bovine serum, commonly used for this purpose (15). In addition, FF has been extensively explored in several works: biochemical constitution $(13,16,17)$, factors that may influence or modify their production, such as climate (18) or nutrition (19), as well as its interference in the process of maturation of bovine embryo $(14,20)$.

Follicular fluid is formed through the transudation of the fluid produced by the theca and granulosa cells in the follicular antrum. This phenomenon occurs during the growth phase of the follicles, which increases the pressure inside the follicular antrum, expelling the fluid present there. Its composition and quantity can be modified during the development of the follicle $(21,22)$. Among its components, steroids and glycoproteins are found, which are synthesized by dominant follicular cells, and are part of the specific constituents of FF, as well as other factors or substances that are synthesized by ovarian somatic cells; these compounds contribute to the metabolism of cells and follicular oocyte $(16,23,24)$. Also in the composition, there is a variety of polyunsaturated fatty acids, with linoleic acid found in larger quantities in small follicles. It is hypothesized that this may be one of the molecules responsible for inhibition of meiosis in bovine oocytes (25). More recently, studies related to estrogen activity with the composition of the fatty acids present in the FF of dairy cows, remaining different from the composition found in plasma (26).

Studying the composition of FF is of great importance, since it may be used as an evaluation parameter of oocyte quality, which can be directly related to fertility (27). In this way, FF analysis can be employed in livestock breeding strategies with the aim of improving milk and meat production. Commercial interest, therefore, implies the development of analytical techniques that provide fast and reliable results that are cost-effective at the same time to evaluate and characterize target compounds in $\operatorname{FF}(13,27$, 28). For this type of analysis, liquid chromatography techniques are commonly used, for example, LC-MS or HPLC-MS. For untargeted metabolomics screenings, however, LC-MS based systems are a considerably demanding alternative in terms of time and costs to identify unknown compounds in complex samples $(29,30)$. This is intimately related to the need of isolating compounds of interest first, and then performing characterization through comparison with certified standards (30), which makes it a much more suitable technique to be used in target analysis (31). In comparison to chromatography techniques, direct-infusion mass spectrometry (DIMS) with mass-selective detection is capable of providing high specificity chemical information, which includes molecular mass and/or characteristic information of the fragmented ions. This information can be used to identify compounds by matching the spectrum obtained with the data collected in databases of authentic compounds or to be used for de novo structural elucidation (31).

There is still little knowledge on the metabolomic profile of FF and, given the versatility of DIMS in providing fingerprints and selecting markers in biological samples (32-35), high-resolution mass spectrometry (HRMS) is ideal for fast screening, with minimal sample preparation and a high-throughput analytical process in shotgun lipidomic approach (36). The present study demonstrates the potential of HRMS to provide biomarkers for high and low fertility in cows (Bos indicus) from samples of FF, where it was possible to assign molecular markers to each group within a biochemical context, thereby demonstrating the sensitivity of this new methodology.

\section{MATERIALS AND METHODS}

\section{Animals}

The Institutional Committee for Ethics in Animal Research of the University of Campinas (UNICAMP) is the body responsible for approving the handling of cattle used in this study. This academic institution follows the Ethical Principles of Animal Research, as established by the Brazilian College for Animal Experimentation (COBEA). Protocol number 2819-1 refers to this process and the research was executed strictly in accordance with the Public Health Service Policy.

The animals $(n=29)$ were bred in a tropical climate region (CwA Köppen classification), characterized by a rainy, hot summer, and a dry winter. The criteria used to select the animals in the study were: non-lactating mature Nellore (Bos indicus); age $=4-7$ years old; body weight $=439 \pm 20 \mathrm{~kg}$. All cows were maintained on pasture (Brachiaria decumbens and Brachiaria brizantha) with mineral supplementation and water available ad libitum.

\section{Follicular Fluid}

Samples of FF were obtained from all cows by follicular aspiration from ovaries with presence of corpora lutea and follicle diameter ranged $10-14 \mathrm{~mm}$. FF was centrifuged at $1,000 \mathrm{x} g$ for $1 \mathrm{~min}$, and the supernatant was stored for analysis at $-80^{\circ} \mathrm{C}$. Samples were divided in three groups after FF aspiration, using the following the criteria: 12 animals that produced a higher number of oocytes (considered as $n>15$ ), 9 animals that produced a lower number of oocytes $<5$, and 8 for control group, i.e., those producing an intermediate number of oocytes (considered as $5<n<15$ ).

For analysis, samples were prepared by dilution $(10: 990 \mathrm{v} / \mathrm{v})$ of FF in a solution of methanol and water $(50: 50 \mathrm{v} / \mathrm{v})$. This first solution was filtered through $0.22-\mu \mathrm{m}$ polyvinylidene difluoride membranes and resuspended $(10: 990 \mathrm{v} / \mathrm{v})$ in a solution of methanol and water $(50: 50 \mathrm{v} / \mathrm{v})$, resulting in a second solution. The second solution was divided in two vials ( $500 \mu \mathrm{L}$ each) and 
either formic acid or ammonium hydroxide was added to a $0.1 \%$ concentration for analysis in positive and negative mode, respectively. All samples were prepared in triplicates. Methanol, ammonium hydroxide, and formic acid were purchased from J. T. Baker (Xalostoc, Mexico) and used with no further purification. Deionized water was obtained from a Milli-Q system (Millipore, USA).

\section{High-Resolution Mass Spectrometry}

After preparation, all samples were injected for fingerprint analysis on an Orbitrap Discovery ESI-LTQ-XL instrument (Thermo Fisher Scientific, Bremen, Germany) with a nominal resolution of 30,000 (FWHM). Analyses were carried out in the mass range of $200-800 \mathrm{~m} / \mathrm{z}$. The instrument run was configured according to the following parameters: flow rate of $10 \mu \mathrm{L} \mathrm{min}{ }^{-1}$, capillary temperature of $280^{\circ} \mathrm{C}, 5 \mathrm{kV}$ of spray voltage, and sheath gas in 10 arbitrary units. HRMS acquisitions were performed in quintuplicates, and in both modes, positive and negative.

\section{Statistical Analysis and Biomarker Identification}

The method of choice to evaluate the association between the groups was the partial least squares discriminant analysis (PLS-DA) with the variable importance in projection (VIP) score. This is a supervised method that uses multivariate regression techniques to extract features from each group and show the existence or not of differences and similarities between the analyzed samples. The statistical significance of the model obtained by PLS-DA was assessed by the application of two permutation tests: 10 -fold cross validation and leave-one-out cross validation. Establishing a VIP score threshold greater than 3.0 was possible to perform the selection of characteristic biomarkers for each group. VIP score consists of the weighted average of squares of PLS loads and takes into account the amount of variance explained in each dimension used in the model. All chosen markers from the VIP scores list were submitted to receiver operating characteristics (ROC) curve analyses in order to verify the probability that each molecule had of belonging to their specific group. A heatmap of the markers elected was built using the Euclidean distance measurement and Ward clustering algorithms. All statistical analyses were performed using the online platform MetaboAnalyst 3.0 (37). For the structural elucidation of the markers, mass accuracy was the main parameter, by comparing the mass values obtained experimentally and those available in online databases, such as METLIN (Scripps Center for Metabolomics, La Jolla, CA, USA), in order to guide the choice of potential markers for the quality of bovine oocytes. A molecule was deemed characterized when presented an identification error value of less than $2 \mathrm{ppm}$.

\section{RESULTS}

Figure 1 shows the clustering graphs of PLS-DA analysis, where it was possible to assess separation among all groups, in both ion modes: positive (Figure 1A) and negative (Figure 1B). Statistical and chemical analyses combined provided all markers, as follows: 7 candidates for the group with a higher number of oocytes, split into three markers for the positive ion mode and four for the negative ion mode, and two candidate markers selected for the

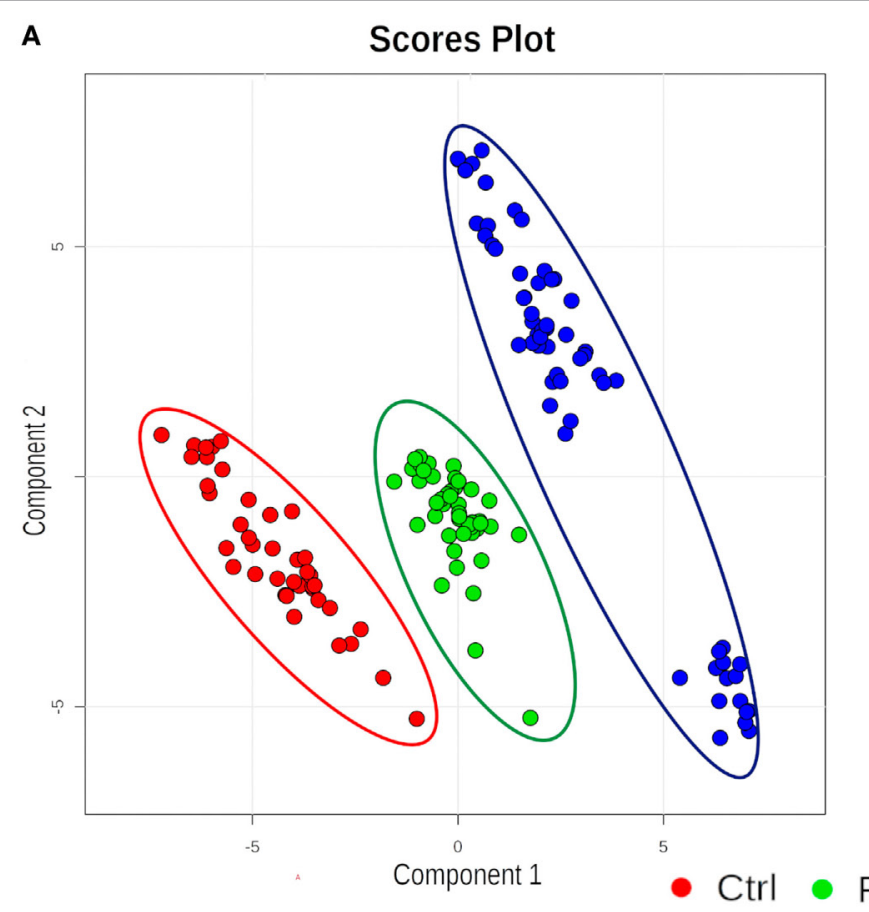

$\mathbf{B}$

Scores Plot

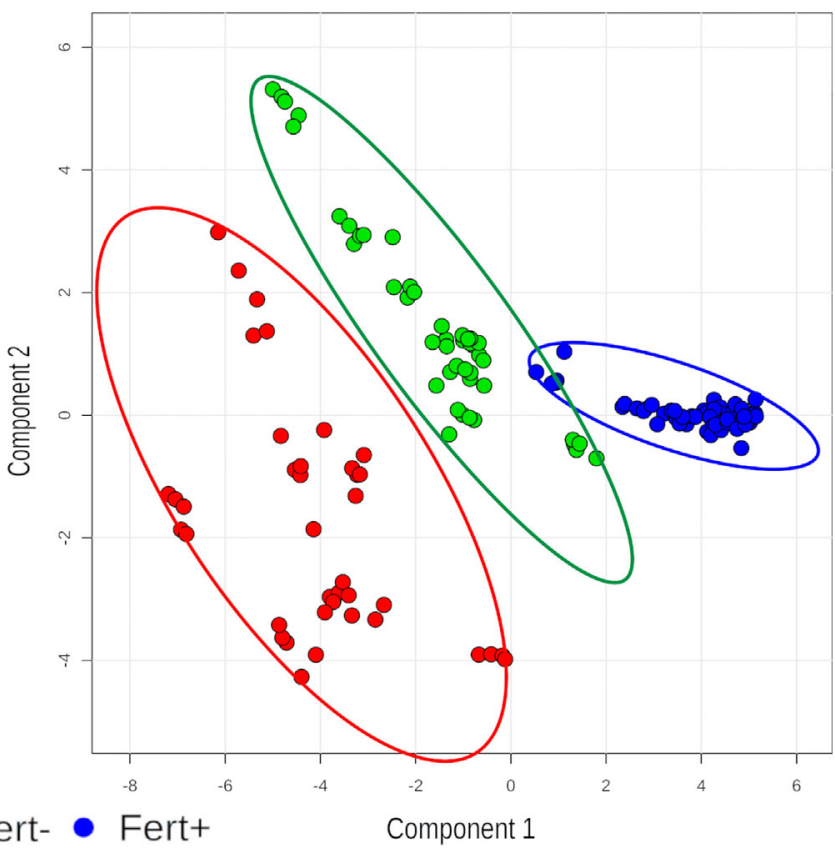

FIGURE 1 | Clustering graphs of partial least squares discriminant analysis analysis for all groups (Ctrl, control; Fert+, higher number of oocytes; Fert-, lower number of oocytes) at positive (A) and negative (B) ion mode. 
group with a lower number of oocytes, split as one in the negative and one in the positive ion mode. The compounds are organized in Table 1.

According to the ROC curve analysis, the group with higher number of oocytes achieved satisfactory results on both negative and positive ion modes. The three markers for the high number of oocytes group in the positive ion mode presented an area under the curve (AUC) value of $0.996(0.978-1.00)$, with a sensitivity and specificity values of $0.950(0.851-0.987)$ and $0.992(0.950-1.000)$, respectively (Figure 2A). In addition, the four markers obtained in the negative ion mode for the same group achieved an AUC of $0.999(0.996-1.000)$ with sensitivity and specificity values of 0.932 (0.827-0.978) and 1.000 (0.961-1.000), respectively (Figure 2B). A similar behavior was observed with the markers selected for the group with lower number of oocytes; the marker selected from the positive ion mode presented an AUC of 0.968 (0.954-0.985) with values of sensitivity and specificity of $0.978(0.868-0.999)$ and 0.864 (0.794-0.914), respectively (Figure 3A). Finally, the marker from the negative ion mode in the same group was achieved an AUC of 0.861 (0.756-0.930) with values of sensitivity and specificity of $0.733(0.578-0.849)$ and $0.887(0.817-0.933)$, respectively (Figure 3B). The selected and characterized markers are presented in the Heatmap (Figure 4), showing the presence or absence of these markers among the groups.

\section{DISCUSSION}

Results indicated a remarkable possibility of employing FF analysis as a reliable test to predict whether a particular animal will present a higher or lower number of oocyte production rate. This information is important, as the number of oocytes was directly related to the increased fertility in cows; hence, the

TABLE 1 | Biomarkers of the groups of high and low number of oocytes in the positive and negative modes of analysis.

\begin{tabular}{|c|c|c|c|c|c|c|}
\hline & $\begin{array}{c}\text { Experimental } \\
\text { mass }\end{array}$ & $\begin{array}{c}\text { Theoretical } \\
\text { mass }\end{array}$ & Error (ppm) & Adduct & Compound & MID* \\
\hline \multirow[t]{7}{*}{ Higher number of oocytes } & 429.0954 & 429.0946 & 1.8644 & {$[\mathrm{M}+\mathrm{K}]^{+}$} & Resveratrol 4'-glucoside & 87064 \\
\hline & 455.1715 & 455.1706 & 1.9773 & {$\left[\mathrm{M}+\mathrm{H}-\mathrm{H}_{2} \mathrm{O}\right]^{+}$} & Lupinisoflavone $\mathrm{N}$ & 47791 \\
\hline & 667.1881 & 667.1869 & 1.7986 & {$[\mathrm{M}+\mathrm{H}]^{+}$} & Peonidin acetyl 3,5-diglucoside & 47015 \\
\hline & 243.0659 & 243.0663 & 1.6539 & {$[\mathrm{M}-\mathrm{H}]^{-}$} & 3,3',4,5'-Tetrahydroxy-trans-stilbene & 7029 \\
\hline & 319.1328 & 319.1334 & 1.9114 & {$\left[\mathrm{M}-\mathrm{H}_{2} \mathrm{O}-\mathrm{H}\right]^{-}$} & 5,7-dihydroxy-6-methyl-8-prenylflavanone & 52673 \\
\hline & 335.1277 & 335.1283 & 1.8202 & {$[\mathrm{M}-\mathrm{H}]^{-}$} & Xanthohumol & 52097 \\
\hline & 363.1223 & 363.1216 & 1.9277 & {$[\mathrm{M}+\mathrm{Cl}]^{-}$} & Prostaglandin M & 45949 \\
\hline \multirow[t]{2}{*}{ Lower number of oocytes } & 476.3168 & 476.3159 & 1.8895 & {$[\mathrm{M}+\mathrm{H}]^{+}$} & N-docosahexaenoyl phenylalanine & 75476 \\
\hline & 336.3260 & 336.3266 & 1.8137 & {$\left[\mathrm{M}-\mathrm{H}_{2} \mathrm{O}-\mathrm{H}\right]^{-}$} & N-Eicosanoyl-ethanolamine & 3724 \\
\hline
\end{tabular}

${ }^{*} M E T L I N I D$.
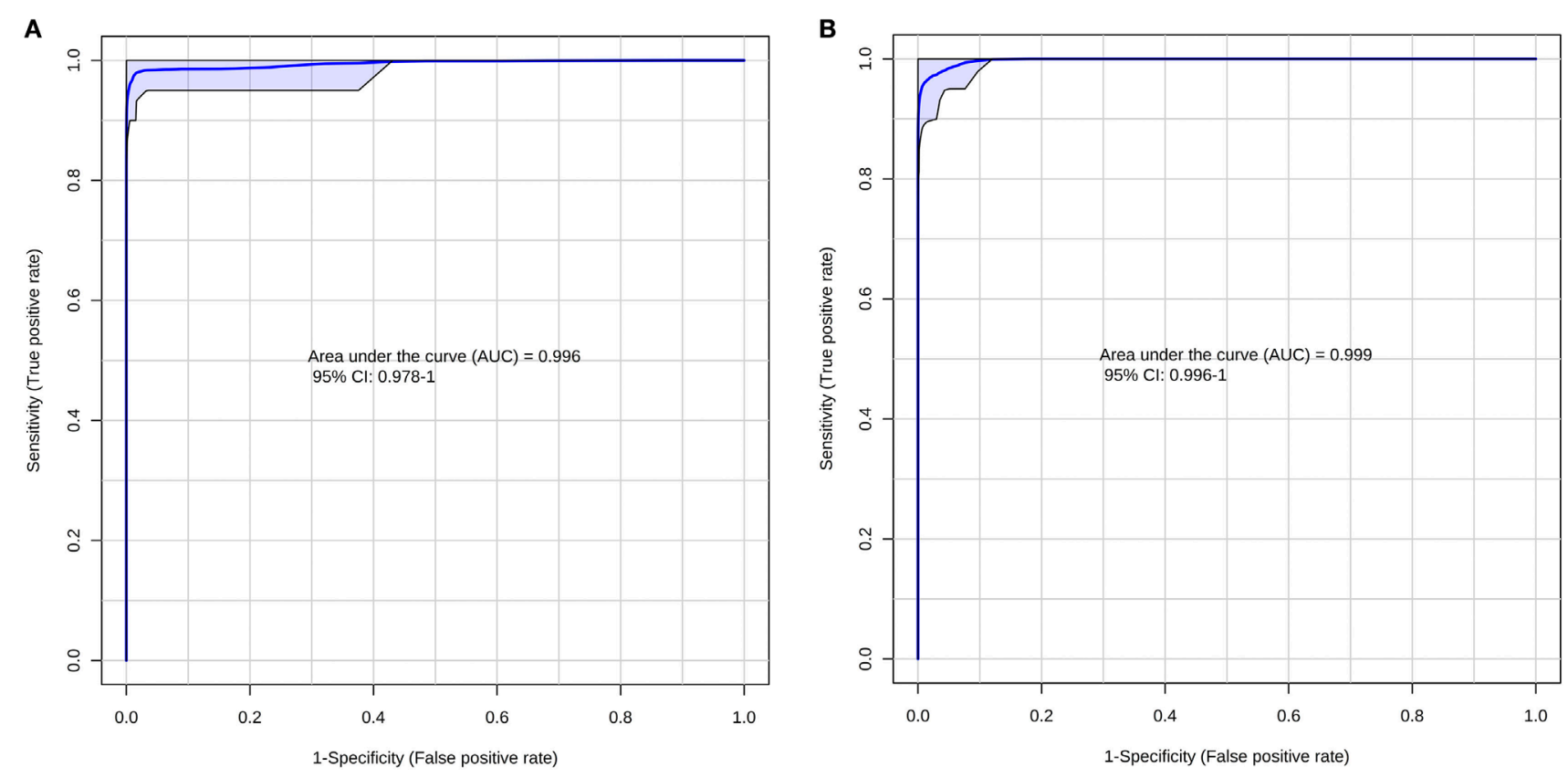

FIGURE 2 | Receiver operating characteristics curve for the group with higher number of oocytes at positive (A) and negative (B) ion mode. 

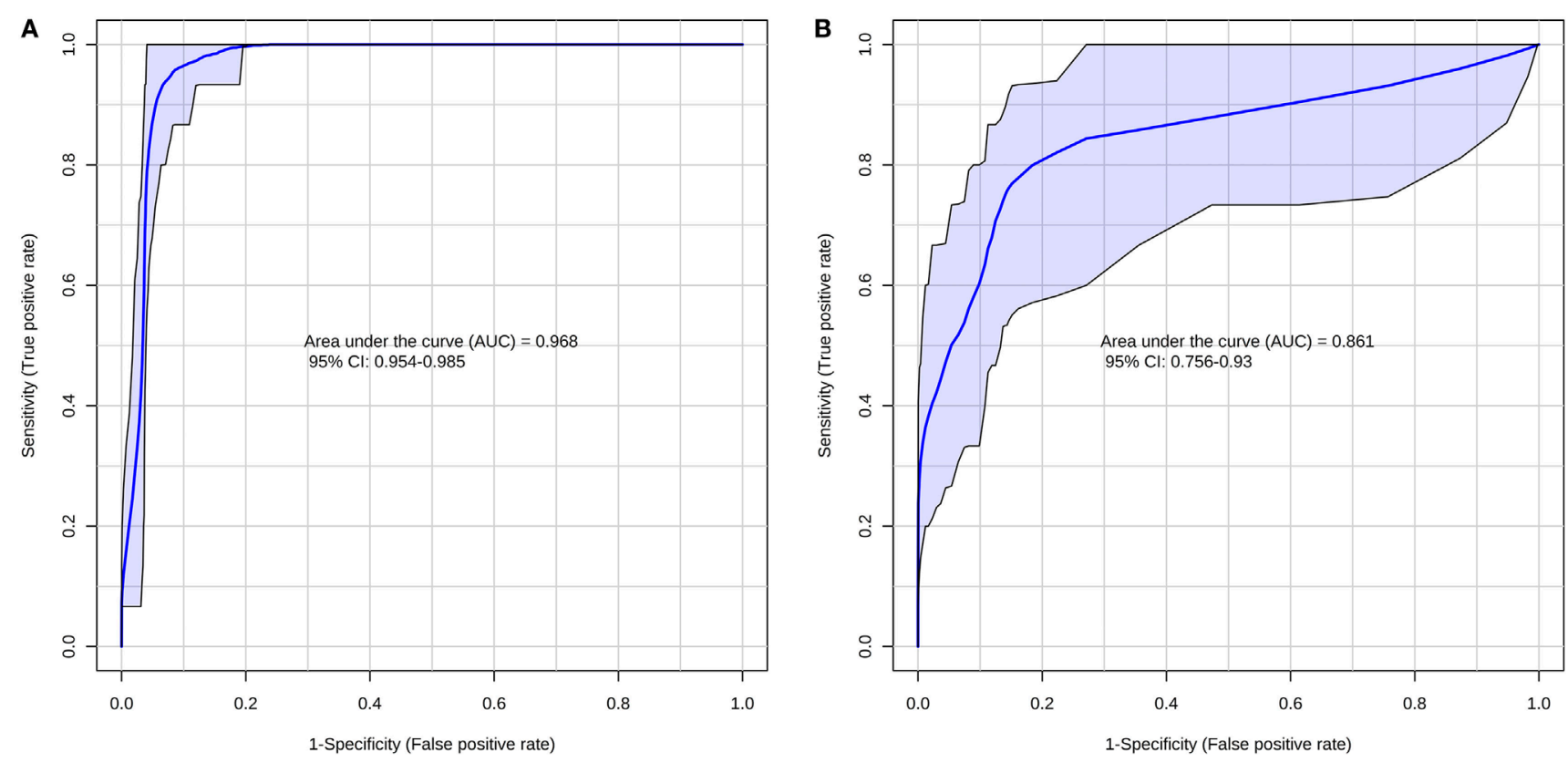

FIGURE 3 | Receiver operating characteristics curve for the group with lower number of oocytes at positive (A) and negative (B) ion mode.

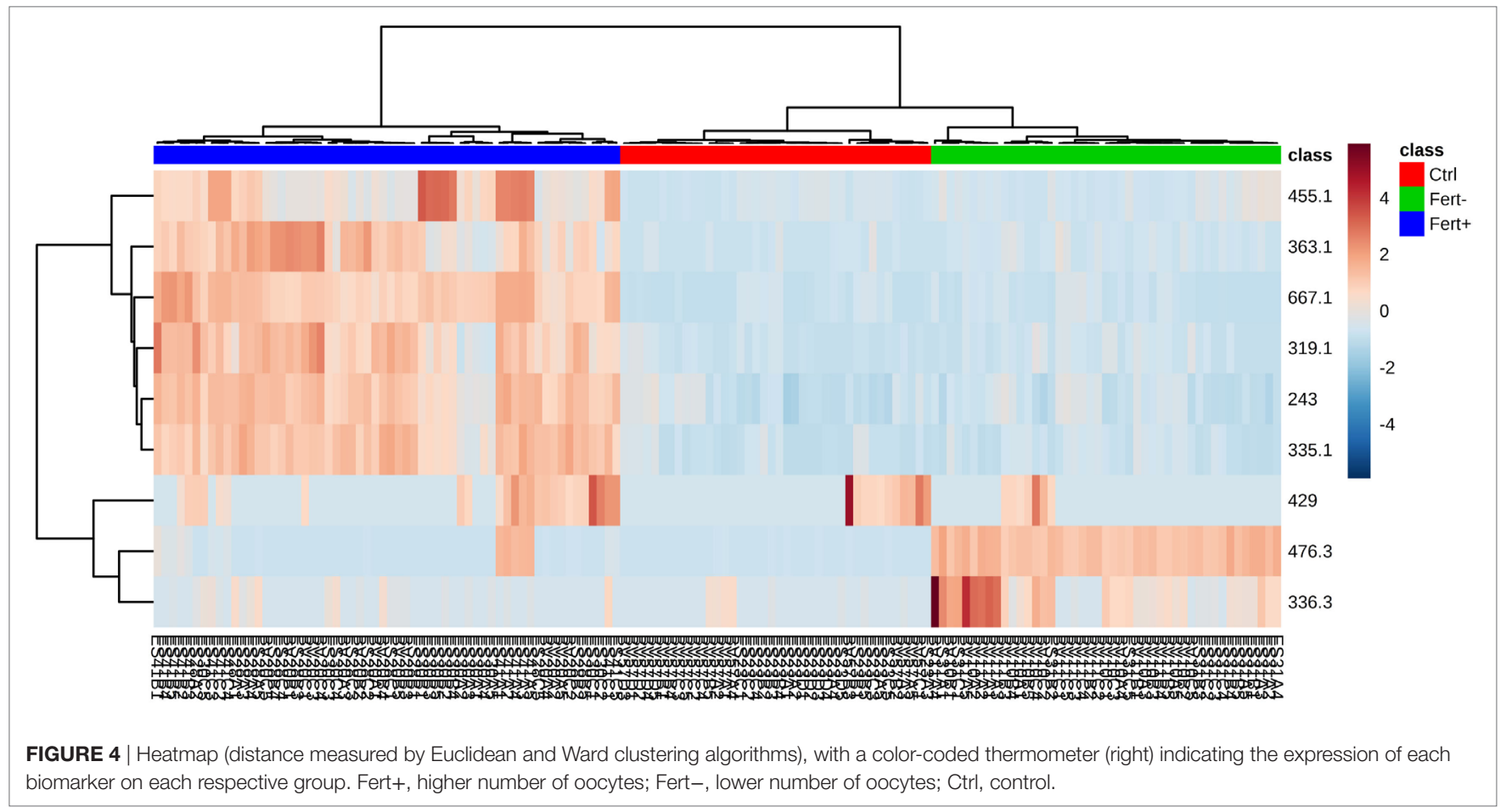

higher the number, the greater will be the chance of reproduction (38). From the results in Table 1, it is possible to infer two main differences: in the group of animals with low oocyte number, the statistical model elected compounds that are directly related to an inflammatory state that, consequently, increases oxidative stress and, even more interestingly, may also be involved with negative hormonal feedback. On the other hand, for the high oocyte number group, compounds were mostly phenolics and flavonoids, i.e., species that are probably incorporated from feed, given their non-endogenous character, and are closely related to protection against oxidative stress in the embryo-developing environment. 
In the low oocyte production group, $\mathrm{N}$-docosahexaenoyl phenylalanine was elucidated in the positive mode, and $\mathrm{N}$-eicosanoyl ethanolamine in the negative mode. $N$-docosahexaenoyl phenylalanine is part of the group of $\mathrm{N}$-acyl amides and $\mathrm{N}$-eicosanoyl ethanolamine is part of the group of $N$-acyl ethanolamines. These compounds constitute a general class of endogenous simple fatty amides, characterized by an acyl group bonded to a nitrogenated moiety, i.e., a conjugated system that comprises putative signaling molecules with a wide range of biological activity (39). The best-known subgroup of this classification would be the endocannabinoids, which are endogenously produced lipids capable of binding to cannabinoid receptors. In addition, other types of endogenous lipids, similar to endocannabinoids in structure, are not capable to bind with cannabinoid receptors. Despite that, they demonstrate cannabimimetic effects, similar to the markers found in this work (39).

Cannabinoid receptors 1 and 2 (CB1 and CB2) have been described in human endometrium (40), where CB1 signalizes for the transport of embryos through the oviduct (41) as well as for embryo establishment in the womb (42). Recent contributions have shown that the endocannabinoid anandamide plays an important role during the fertilization process in humans (43), as well as the influence of anandamide in the estrous cycle in bovines has been also reported (44). Given that the ovulation process is quite similar in mammalians, it was shown in both studies that high concentrations of anandamide are related to the hormonal peak of estradiol during ovulation, responsible for the release of the ovule. In addition, it has been reported that high levels of anandamide in humans are related to early pregnancy loss (45) and reduction in levels of progesterone (40), a key hormone for both implantation of the ovum and maintenance of pregnancy $(43,46,47)$. As $N$-docosahexaenoyl phenylalanine has cannabimimetic effects, its presence in the FF of cows from the lower oocyte number group could be related to this hormonal regulation presented by anandamide. In the case of $N$-eicosanoyl ethanolamine, its presence might be related to the "entourage effect," in which these $N$-acyl ethanolamines inhibit anandamide degradation through their ability to compete for fatty acid amide hydrolase, since both compounds are hydrolyzed by the same enzymatic reaction. With increasing levels of anandamide, progesterone remains low; this condition does not allow the occurrence of positive pregnancy, as the high concentration of progesterone in FF is related to the increase of fertility in cattle $(46,47)$.

Moreover, eicosanoids and docosanoids are extensively described in literature as key intermediates in the inflammation cascade, and their presence is often regarded as associated with an existing condition that may be associated to an inflammatory process (48). The influence of inflammation and the underlying oxidative environment caused by this process are also widely discussed regarding their negative influence over reproduction (49). Therefore, the election of $\mathrm{N}$-docosahexaenoyl phenylalanine and $\mathrm{N}$-eicosanoyl ethanolamine as markers for the low oocyte number group also make sense considering the potential oxidative stress existing in animals from these groups.

Regarding the high oocyte number group, by observing Table 1, we find Resveratrol 4' -glucoside, Lupinisoflavone N, and
Peonidin acetyl 3,5-diglucoside in the positive ion mode; on the other hand, in the negative mode, we find 3,3',4,5' -tetrahydroxytrans-stilbene, 5,7-dihydroxy-6-methyl-8-prenylflavanone, xanthohumol, and prostaglandin $M$. The main characteristic that is common to great majority of these species is the antioxidant character associated with these compounds, as oocytes and embryos are highly vulnerable to oxidative stress and other conditions when cultured in vitro (50).

Resveratrol 4'-glucoside and 3,3',4,5'-tetrahydroxy-transstilbene, or piceatannol, are compounds that belong to the class of stilbenes. Piceatannol is a metabolite of resveratrol that has greater antioxidant potential than its precursor due to the position of its hydroxyl groups, which favors the capture of free radicals (51). Some contributions in the literature have discussed the benefits of resveratrol during mammalian reproduction, including the improvement on the quality of bovine embryos when added during oocyte maturation, making these embryos more resistant during cryopreservation (52). In addition, when resveratrol was consumed for a longer period, it improved and increased the number of oocytes produced by female mice (52). Since the cows in this study were fed green pasture, it is plausible to have Resveratrol 4' -glucoside elected as a marker for the group of cows with high oocyte number production, as its high antioxidant potential (53) favors both the oocyte maturation process and the future development of new embryos in cattle.

The other elected markers may also be attributed to come from the diet and belong to the family of flavonoids, which are compounds characterized by the presence of interconnected phenolic rings, directly related to the antioxidant potential presented by its members (54). This family has several subclassifications of its components, according to specific characteristics of the chemical structure they present, being able to comprise isoflavones, anthocyanidins, and prenylflavonoids, which have, respectively, the markers Lupinisoflavone $\mathrm{N}$, peonidin acetyl 3,5-diglucoside, 5,7-dihydroxy-6-methyl-8-prenylflavanone, and xanthohumol. Lupinisoflavone $\mathrm{N}$, which is an isoflavone found in plants of the genus Lupine, from the family Leguminosae (55). Isoflavones are phenolic compounds and have a well-known antioxidant character $(56,57)$; studies have shown that supplementation of animal feeding with lupines is related to increased ovulation rate in sheep (58) and also to improved reproductive efficiency in the case of ruminants (59). Peonidin acetyl 3,5-diglucoside belongs to the class of anthocyanins, a class of flavonoids with high antioxidant potential (60-62). With respect to these characteristic, we have another marker that could be collaborating for the development of embryos due to its ability to protect oocytes from free radicals or reactive oxygen species (ROS) (62).

Regarding the subclass of prenylflavonoids, we have 5,7dihydroxy-6-methyl-8-prenylflavanone and xanthohumol. This class of bioactive compounds are prenylated phenylalanine derivatives formed in the plant secondary metabolism and may be found in several species. The activity of this class relies on phytoestrogenic and antioxidant properties (63), and studies have shown that xanthohumol has anticancer, antidiabetic, antibacterial, and anti-inflammatory activities $(64,65)$. These characteristics may be related to its antioxidant capacity, since xanthohumol can act directly reducing the formation of ROS, or indirectly through the 
induction of cellular defense mechanisms against oxidative stress, thus contributing to the improvement of several diseases related to ROS (65-68). The presence of compounds such as xanthohumol in the FF may be traced back directly to the animal's feed, since flavonoids and its derivatives are ubiquitous to the metabolism of several plant species, especially grasses such as $B$. decumbens and $B$. brizantha $(69,70)$, which were used in the pastures of the animals in this study.

Finally, the last marker found in the negative mode for the high fertility group was Prostaglandin M. Prostaglandins (PGE) are a group of physiologically active lipids due to their ability to generate hormonal responses in animals. PGE-M is a metabolite of PGE-2 (71), which in turn is directly linked to ovulation as it increases its levels when there is an increase in luteinizing hormone (72). PGE-2 is one of several signaling molecules that, together with the follicle, are able to coordinate oocyte maturation, and enhanced expression of proteases associated with follicle rupture, which ensures the release of an optimally mature oocyte during ovulation (73-75). Hence, the presence of PGE-M as a marker of the high oocyte number group is indicative of a higher performance of PGE-2 in the animals of this group.

Through our findings, it was possible to establish a link between markers found in bovine FF and oocyte quality/production rate. Incidentally, we expected that the relevant compounds were simply derived from feed and that are also potentially related to the increase of fertility in cows, since they were the chosen markers for the group of animals with higher production of oocytes. As we observed, however, the inflammatory status of the animals is what indeed plays a key role in the oocyte production and, ultimately survival; docosanoids and eicosanoids, the molecular classes observed in the low oocyte group, are well-known players involved in reactions that lead to inflammatory state in organisms. This provides evidence that, even though the feed is the same for both animal groups, there is an important depletion of

\section{REFERENCES}

1. Walsh S, Williams E, Evans A. A review of the causes of poor fertility in high milk producing dairy cows. Anim Reprod Sci (2011) 123(3):127-38. doi:10.1016/j.anireprosci.2010.12.001

2. Giordano J, Wiltbank M, Guenther J, Pawlisch R, Bas S, Cunha A, et al. Increased fertility in lactating dairy cows resynchronized with Double-Ovsynch compared with Ovsynch initiated $32 \mathrm{D}$ after timed artificial insemination. J Dairy Sci (2012) 95(2):639-53. doi:10.3168/jds. 2011-4418

3. Bisinotto R, Ribeiro E, Lima F, Martinez N, Greco L, Barbosa L, et al. Targeted progesterone supplementation improves fertility in lactating dairy cows without a corpus luteum at the initiation of the timed artificial insemination protocol. J Dairy Sci (2013) 96(4):2214-25. doi:10.3168/jds.2012-6038

4. Butler W. Nutritional interactions with reproductive performance in dairy cattle. Anim Reprod Sci (2000) 60:449-57. doi:10.1016/S0378-4320(00) 00076-2

5. López-Gatius F. Is fertility declining in dairy cattle? A retrospective study in northeastern Spain. Theriogenology (2003) 60(1):89-99. doi:10.1016/ S0093-691X(02)01359-6

6. Vanholder T, Leroy J, Van Soom A, Opsomer G, Maes D, Coryn M, et al. Effect of non-esterified fatty acids on bovine granulosa cell steroidogenesis and proliferation in vitro. Anim Reprod Sci (2005) 87(1):33-44. doi:10.1016/j. anireprosci.2004.09.006 antioxidants in the low oocyte group due to a potentially high oxidative stress to which these animals are subjected. Hence, antioxidants are in high levels for the high-oocyte animals and, therefore, were elected as markers, as opposed to the low-oocyte, which present an inflammatory picture, traced back from the molecular classes elected by PLS-DA.

\section{ETHICS STATEMENT}

The Institutional Committee for Ethics in Animal Research of the University of Campinas (UNICAMP) is the body responsible for approving the handling of cattle used in this study. This academic institution follows the Ethical Principles of Animal Research, as established by the Brazilian College for Animal Experimentation (COBEA). Protocol number 2819-1 refers to this process and the research was executed strictly in accordance with the Public Health Service Policy.

\section{AUTHOR CONTRIBUTIONS}

RG, JV, and MA performed sample collection. TG performed experiments and wrote the manuscript. TG and CM performed data analysis. DO and EL performed manuscript review. RC idealized all experiments and managed the research group.

\section{FUNDING}

The authors would like to thank the São Paulo Research Foundation (FAPESP) for the financial support provided through process Nos.: 2010/01077-9, 2011/18085-7, 2011/50400-0, 2015/06809-1, and 2016/17066-2. The authors would also like to thank the Coordination for the Improvement of Higher Education Personnel (CAPES) for the fellowships provided through process Nos. 1489740, 1645986, 1578388.

7. Sirard M-A, Richard F, Blondin P, Robert C. Contribution of the oocyte to embryo quality. Theriogenology (2006) 65(1):126-36. doi:10.1016/j. theriogenology.2005.09.020

8. Revelli A, Delle Piane L, Casano S, Molinari E, Massobrio M, Rinaudo P. Follicular fluid content and oocyte quality: from single biochemical markers to metabolomics. Reprod Biol Endocrinol (2009) 7(1):40. doi:10.1186/ 1477-7827-7-40

9. Richards JS, Russell DL, Robker RL, Dajee M, Alliston TN. Molecular mechanisms of ovulation and luteinization. Mol Cell Endocrinol (1998) 145(1):47-54. doi:10.1016/S0303-7207(98)00168-3

10. Gosden R, Hunter R, Telfer E, Torrance C, Brown N. Physiological factors underlying the formation of ovarian follicular fluid. J Reprod Fertil (1988) 82(2):813-25. doi:10.1530/jrf.0.0820813

11. Leroy J, Vanholder T, Mateusen B, Christophe A, Opsomer G, de Kruif A, et al. Non-esterified fatty acids in follicular fluid of dairy cows and their effect on developmental capacity of bovine oocytes in vitro. Reproduction (2005) 130(4):485-95. doi:10.1530/rep.1.00735

12. McNatty KP. Cycle changes in antral fluid hormone concentrations in humans. Clin Endocrinol Metab (1978) 7(3):577-600. doi:10.1016/ S0300-595X(78)80010-3

13. Bender K, Walsh S, Evans AC, Fair T, Brennan L. Metabolite concentrations in follicular fluid may explain differences in fertility between heifers and lactating cows. Reproduction (2010) 139(6):1047-55. doi:10.1530/REP10-0068 
14. Lehmkuhl R, Mezzalira A, Vieira A, Barbieri D, Machado M, Rubin M, et al. Viabilidade de oócitos bovinos mantidos em líquido folicular. Ars Vet (2002) 18(3):273-9.

15. Romero-Arredondo A, Seidel G. Effects of bovine follicular fluid on maturation of bovine oocytes. Theriogenology (1994) 41(2):383-94. doi:10.1016/ 0093-691X(94)90074-S

16. Nandi S, Kumar VG, Manjunatha B, Gupta P. Biochemical composition of ovine follicular fluid in relation to follicle size. Dev Growth Differ (2007) 49(1):61-6. doi:10.1111/j.1440-169X.2007.00901.x

17. Nishimoto H, Hamano S, Hill GA, Miyamoto A, Tetsuka M. Classification of bovine follicles based on the concentrations of steroids, glucose and lactate in follicular fluid and the status of accompanying follicles. J Reprod Dev (2009) 55(2):219-24. doi:10.1262/jrd.20114

18. Lew B, Meidan R, Wolfenson D. Concentrações hormonais e desenvolvimento folicular de vacas leiteiras em hipertermia sazonal e aguda. Arq Bras Med Vet Zootec (2006) 58:816-22. doi:10.1590/S0102-09352006000500017

19. Santos J, Cerri R, Sartori R. Nutritional management of the donor cow. Theriogenology (2008) 69(1):88-97. doi:10.1016/j.theriogenology.2007.09.010

20. Orsi NM, Gopichandran N, Leese HJ, Picton HM, Harris SE. Fluctuations in bovine ovarian follicular fluid composition throughout the oestrous cycle. Reproduction (2005) 129(2):219-28. doi:10.1530/rep.1.00460

21. Wise T. Biochemical analysis of bovine follicular fluid: albumin, total protein, lysosomal enzymes, ions, steroids and ascorbic acid content in relation to follicular size, rank, atresia classification and day of estrous cycle. J Anim Sci (1987) 64(4):1153-69. doi:10.2527/jas1987.6441153x

22. Fortune J, Rivera G, Yang M. Follicular development: the role of the follicular microenvironment in selection of the dominant follicle. Anim Reprod Sci (2004) 82:109-26. doi:10.1016/j.anireprosci.2004.04.031

23. Lonergan P, Monaghan P, Rizos D, Boland M, Gordon I. Effect of follicle size on bovine oocyte quality and developmental competence following maturation, fertilization, and culture in vitro. Mol Reprod Dev (1994) 37(1):48-53. doi:10.1002/mrd.1080370107

24. Gerard N, Loiseau S, Duchamp G, Seguin F. Analysis of the variations of follicular fluid composition during follicular growth and maturation in the mare using proton nuclear magnetic resonance (1H NMR). Reproduction (2002) 124(2):241-8. doi:10.1530/rep.0.1240241

25. Homa S, Brown C. Changes in linoleic acid during follicular development and inhibition of spontaneous breakdown of germinal vesicles in cumulusfree bovine oocytes. J Reprod Fertil (1992) 94(1):153-60. doi:10.1530/jrf. 0.0940153

26. Renaville B, Bacciu N, Comin A, Motta M, Poli I, Vanini G, et al. Plasma and follicular fluid fatty acid profiles in dairy cows. Reprod Domest Anim (2010) 45(1):118-21. doi:10.1111/j.1439-0531.2008.01264.x

27. Matoba S, Bender K, Fahey AG, Mamo S, Brennan L, Lonergan P, et al. Predictive value of bovine follicular components as markers of oocyte developmental potential. Reprod Fertil Dev (2014) 26(2):337-45. doi:10.1071/ RD13007

28. Zachut M, Sood P, Levin Y, Moallem U. Proteomic analysis of preovulatory follicular fluid reveals differentially abundant proteins in less fertile dairy cows. J Proteomics (2016) 139:122-9. doi:10.1016/j.jprot.2016.03.027

29. Wilson ID, Plumb R, Granger J, Major H, Williams R, Lenz EM. HPLC-MSbased methods for the study of metabonomics. J Chromatogr B Analyt Technol Biomed Life Sci (2005) 817(1):67-76. doi:10.1016/j.jchromb.2004.07.045

30. Theodoridis G, Gika HG, Wilson ID. LC-MS-based methodology for global metabolite profiling in metabonomics/metabolomics. Trends Anal Chem (2008) 27(3):251-60. doi:10.1016/j.trac.2008.01.008

31. Bedair M, Sumner LW. Current and emerging mass-spectrometry technologies for metabolomics. Trends Anal Chem (2008) 27(3):238-50. doi:10.1016/j. trac.2008.01.006

32. Ferreira MS, de Oliveira DN, Gonçalves RF, Catharino RR. Lipid characterization of embryo zones by silica plate laser desorption ionization mass spectrometry imaging (SP-LDI-MSI). Anal Chim Acta (2014) 807:96-102. doi:10.1016/j.aca.2013.11.033

33. Lima EDO, de Macedo CS, Esteves CZ, de Oliveira DN, Pessolani MCV, Nery JADC, et al. Skin imprinting in silica plates: a potential diagnostic methodology for leprosy using high-resolution mass spectrometry. Anal Chem (2015) 87(7):3585-92. doi:10.1021/acs.analchem.5b00097

34. Gonçalves RF, Ferreira MS, de Oliveira DN, Canevarolo R, Achilles MA, D'Ercole DL, et al. Analysis and characterisation of bovine oocyte and embryo biomarkers by matrix-assisted desorption ionisation mass spectrometry imaging. Reprod Fertil Dev (2016) 28(3):293-301. doi:10.1071/RD14047

35. Melo CFO, Delafiori J, de Oliveira DN, Guerreiro TM, Esteves CZ, Lima EDO, et al. Serum metabolic alterations upon Zika infection. Front Microbiol (2017) 8:1954. doi:10.3389/fmicb.2017.01954

36. Schwudke D, Schuhmann K, Herzog R, Bornstein SR, Shevchenko A. Shotgun lipidomics on high resolution mass spectrometers. Cold Spring Harb Perspect Biol (2011) 3(9):a004614. doi:10.1101/cshperspect.a004614

37. Xia J, Sinelnikov IV, Han B, Wishart DS. MetaboAnalyst 3.0 - making metabolomics more meaningful. Nucleic Acids Res (2015) 43(W1):W251-7. doi:10.1093/nar/gkv380

38. Pontes J, Sterza FM, Basso A, Ferreira C, Sanches B, Rubin K, et al. Ovum pick up, in vitro embryo production, and pregnancy rates from a large-scale commercial program using Nelore cattle (Bos indicus) donors. Theriogenology (2011) 75(9):1640-6. doi:10.1016/j.theriogenology.2010.12.026

39. Bradshaw HB, Walker JM. The expanding field of cannabimimetic and related lipid mediators. Br J Pharmacol (2005) 144(4):459-65. doi:10.1038/ sj.bjp.0706093

40. Taylor AH, Abbas MS, Habiba MA, Konje JC. Histomorphometric evaluation of cannabinoid receptor and anandamide modulating enzyme expression in the human endometrium through the menstrual cycle. Histochem Cell Biol (2010) 133(5):557-65. doi:10.1007/s00418-010-0695-9

41. Wang H, Guo Y, Wang D, Kingsley PJ, Marnett LJ, Das SK, et al. Aberrant cannabinoid signaling impairs oviductal transport of embryos. Nat Med (2004) 10(10):1074-80. doi:10.1038/nm1104

42. Paria B, Wang H, Dey S. Endocannabinoid signaling in synchronizing embryo development and uterine receptivity for implantation. Chem Phys Lipids (2002) 121(1):201-10. doi:10.1016/S0009-3084(02)00156-1

43. Wolfson ML, Correa F, Leishman E, Vercelli C, Cymeryng C, Blanco J, et al. Lipopolysaccharide-induced murine embryonic resorption involves changes in endocannabinoid profiling and alters progesterone secretion and inflammatory response by a CB1-mediated fashion. Mol Cell Endocrinol (2015) 411:214-22. doi:10.1016/j.mce.2015.04.032

44. Gervasi MG, Marczylo TH, Lam PM, Rana S, Franchi AM, Konje JC, et al. Anandamide levels fluctuate in the bovine oviduct during the oestrous cycle. PLoS One (2013) 8(8):e72521. doi:10.1371/journal.pone.0072521

45. Habayeb OM, Taylor AH, Finney M, Evans MD, Konje JC. Plasma anandamide concentration and pregnancy outcome in women with threatened miscarriage. JAMA (2008) 299(10):1135-6. doi:10.1001/jama.299.10.1135

46. Wiltbank MC, Souza AH, Carvalho PD, Bender RW, Nascimento AB. Improving fertility to timed artificial insemination by manipulation of circulating progesterone concentrations in lactating dairy cattle. Reprod Fertil Dev (2011) 24(1):238-43. doi:10.1071/RD11913

47. Fair T, Lonergan P. The role of progesterone in oocyte acquisition of developmental competence. Reprod Domest Anim (2012) 47(s4):142-7. doi:10.1111/j.1439-0531.2012.02068.x

48. Jabbour HN, Sales KJ, Catalano RD, Norman JE. Inflammatory pathways in female reproductive health and disease. Reproduction (2009) 138(6):903-19. doi:10.1530/REP-09-0247

49. Agarwal A, Aponte-Mellado A, Premkumar BJ, Shaman A, Gupta S. The effects of oxidative stress on female reproduction: a review. Reprod Biol Endocrinol (2012) 10(1):49. doi:10.1186/1477-7827-10-49

50. Wang F, Tian X, Zhang L, He C, Ji P, Li Y, et al. Beneficial effect of resveratrol on bovine oocyte maturation and subsequent embryonic development after in vitro fertilization. Fertil Steril (2014) 101(2):577-86.e571. doi:10.1016/j. fertnstert.2013.10.041

51. Rossi M, Caruso F, Opazo C, Salciccioli J. Crystal and molecular structure of piceatannol; scavenging features of resveratrol and piceatannol on hydroxyl and peroxyl radicals and docking with transthyretin. J Agric Food Chem (2008) 56(22):10557-66. doi:10.1021/jf801923j

52. Abdel-Wahab A, Zullo G, Boccia L, De Blasi M, Longobardi V, Albero G, et al. 132 resveratrol during in vitro culture improves cryotolerance of in vitro produced bovine embryos. Reprod Fertil Dev (2012) 25(1):213-4. doi:10.1071/ RDv25n1Ab132

53. Mikulski D, Molski M. Quantitative structure-antioxidant activity relationship of trans-resveratrol oligomers, trans- $4,4^{\prime}$-dihydroxystilbene dimer, transresveratrol-3-O-glucuronide, glucosides: trans-piceid, cis-piceid, transastringin and trans-resveratrol-4'-O- $\beta$-D-glucopyranoside. Eur J Med Chem (2010) 45(6):2366-80. doi:10.1016/j.ejmech.2010.02.016 
54. Martins N, Barros L, Ferreira IC. In vivo antioxidant activity of phenolic compounds: facts and gaps. Trends Food Sci Technol (2016) 48:1-12. doi:10.1016/j. tifs.2016.03.009

55. Ranilla LG, Genovese MI, Lajolo FM. Isoflavones and antioxidant capacity of Peruvian and Brazilian lupin cultivars. JFood Compos Anal (2009) 22(5):397-404. doi:10.1016/j.jfca.2008.06.011

56. Miadoková E. Isoflavonoids - an overview of their biological activities and potential health benefits. Interdiscip Toxicol (2009) 2:211-8. doi:10.2478/ v10102-009-0021-3

57. Dixon RA, Pasinetti GM. Flavonoids and isoflavonoids: from plant biology to agriculture and neuroscience. Plant Physiol (2010) 154(2):453-7. doi:10.1104/ pp. 110.161430

58. Stewart R, Oldham C. Feeding lupins to ewes for four days during the luteal phase can increase ovulation rate. Proc Aust Soc Anim Prod Melbourne (1986) 16:367-70.

59. van Barneveld RJ. Understanding the nutritional chemistry of lupin (Lupinus spp.) seed to improve livestock production efficiency. Nutr Res Rev (1999) 12(02):203-30. doi:10.1079/095442299108728938

60. Wang H, Cao G, Prior RL. Oxygen radical absorbing capacity of anthocyanins. J Agric Food Chem (1997) 45(2):304-9. doi:10.1021/jf960421t

61. Dugo P, Mondello L, Morabito D, Dugo G. Characterization of the anthocyanin fraction of sicilian blood orange juice by micro-HPLC-ESI/MS. J Agric Food Chem (2003) 51(5):1173-6. doi:10.1021/jf026078b

62. You J, Kim J, Lim J, Lee E. Anthocyanin stimulates in vitro development of cloned pig embryos by increasing the intracellular glutathione level and inhibiting reactive oxygen species. Theriogenology (2010) 74(5):777-85. doi:10.1016/j.theriogenology.2010.04.002

63. Dufall K, Ngadjui B, Simeon K, Abegaz B, Croft K. Antioxidant activity of prenylated flavonoids from the West African medicinal plant Dorstenia mannii. J Ethnopharmacol (2003) 87(1):67-72. doi:10.1016/S0378-8741(03) 00108-9

64. Stevens JF, Page JE. Xanthohumol and related prenylflavonoids from hops and beer: to your good health! Phytochemistry (2004) 65(10):1317-30. doi:10.1016/j.phytochem.2004.04.025

65. Liu M, Hansen PE, Wang G, Qiu L, Dong J, Yin H, et al. Pharmacological profile of xanthohumol, a prenylated flavonoid from hops (Humulus lupulus). Molecules (2015) 20(1):754-79. doi:10.3390/molecules20010754

66. Miranda CL, Stevens JF, Ivanov V, McCall M, Frei B, Deinzer ML, et al. Antioxidant and prooxidant actions of prenylated and nonprenylated chalcones and flavanones in vitro. J Agric Food Chem (2000) 48(9):3876-84. doi:10.1021/jf0002995

67. Plazar J, Žegura B, Lah TT, Filipič M. Protective effects of xanthohumol against the genotoxicity of benzo (a) pyrene ( $\mathrm{BaP})$, 2-amino-3-methylimidazo $[4,5-f]$ quinoline (IQ) and tert-butyl hydroperoxide (t-BOOH) in HepG2 human hepatoma cells. Mutat Res (2007) 632(1):1-8. doi:10.1016/j. mrgentox.2007.03.013

68. Dorn C, Massinger S, Wuzik A, Heilmann J, Hellerbrand C. Xanthohumol suppresses inflammatory response to warm ischemia-reperfusion induced liver injury. Exp Mol Pathol (2013) 94(1):10-6. doi:10.1016/j.yexmp.2012. 05.003

69. Chitindingu K, Ndhlala A, Chapano C, Benhura M, Muchuweti M. Phenolic compound content, profiles and antioxidant activities of Amaranthus hybridus (pigweed), Brachiaria brizantha (upright Brachiaria) and Panicum maximum (guinea grass). J Food Biochem (2007) 31(2):206-16. doi:10.1111/ j.1745-4514.2007.00108.x

70. Pérez AJ, Hussain SM, Pecio Ł, Kowalczyk M, Herling VR, Stochmal A. Ultrahigh-performance liquid chromatography-high-resolution quadrupole time-of-flight mass spectrometry based metabolomics reveals key differences between Brachiaria decumbens and B. brizantha, two similar pastures with different toxicities. J Agric Food Chem (2016) 64(22):4686-94. doi:10.1021/ acs.jafc.6b01296

71. Heuwieser W, Hoppen HO, Grunert E. Blood levels of prostaglandin metabolites (PGFM, PGEM) after parturition in cows with and without retained placenta considering spontaneous calving and dystocia. Transbound Emerg Dis (1992) 39(1-10):509-14.

72. Duffy DM, McGinnis LK, VandeVoort CA, Christenson LK. Mammalian oocytes are targets for prostaglandin E2 (PGE2) action. Reprod Biol Endocrinol (2010) 8(1):131. doi:10.1186/1477-7827-8-131

73. Tsafriri A, Reich R. Molecular aspects of mammalian ovulation. Exp Clin Endocrinol Diabetes (1999) 107(01):1-11. doi:10.1055/s-0029-1212066

74. Takahashi T, Morrow JD, Wang H, Dey SK. Cyclooxygenase-2-derived prostaglandin E2 directs oocyte maturation by differentially influencing multiple signaling pathways. J Biol Chem (2006) 281(48):37117-29. doi:10.1074/jbc. M608202200

75. Markosyan N, Duffy DM. Prostaglandin E2 acts via multiple receptors to regulate plasminogen-dependent proteolysis in the primate periovulatory follicle. Endocrinology (2009) 150(1):435-44. doi:10.1210/en.2008-0591

Conflict of Interest Statement: The author MA is employed by company Achilles Genetics. All other authors declare no competing interests of any kind.

Copyright (c) 2018 Guerreiro, Gonçalves, Melo, de Oliveira, Lima, Visintin, de Achilles and Catharino. This is an open-access article distributed under the terms of the Creative Commons Attribution License (CC BY). The use, distribution or reproduction in other forums is permitted, provided the original author(s) and the copyright owner are credited and that the original publication in this journal is cited, in accordance with accepted academic practice. No use, distribution or reproduction is permitted which does not comply with these terms. 